\title{
“KARYMAR”: Una etnografía del espacio dancístico
}

\author{
Claudia Lucía López Oviedo* \\ Paola Salazar Arce**
}

\begin{abstract}
RESUMEN
El presente ensayo es el resultado de una investigación de tipo etnográfico, llevada a cabo en el salón de baile "Karymar”, en San José, Costa Rica durante el año 2007. Este salón es uno de los pocos lugares en los cuales se practica el swing criollo, un baile popular costarricense que reúne a bailarines de distintas generaciones en torno a una práctica común. Este estudio aporta nuevas perspectivas al quehacer antropológico, para problematizar las dinámicas sociales que se despliegan a partir de una expresión cultural como es el baile.
\end{abstract}

Palabras clave: Swing criollo, salón de baile, bailarines, música y dinámicas sociales.

\begin{abstract}
The following essay is the result of an ethnographic investigation, which was carried out in dancing hall "Karymar", in San José, Costa Rica, during 2007. This hall its characterized for been one of the few places in which "the swing criollo" can be practiced a Costa Rican popular dance that gather differents generations of dancers around a common practice. This research contribute with new perspectives to the anthropological task, with the social dynamics matter that displays from a culture expression like dance.
\end{abstract}

Keywords: Swing criollo, dancing hall, dancers, music and social dynamics.

\section{Un salón de baile fuera de serie}

Una noche de miércoles, viernes o sábado, luego del trajín cotidiano y de la faena diaria no hay nada mejor que salir de la rutina y, quizás, aventurarse al ritmo de la noche por las calles josefinas con miras de hallar algún sitio que brinde diversión y esparcimiento. ¿Qué tal si se presentara la oportunidad de ir a un espacio social colmado de particularidades a diferencia del resto de los centros nocturnos capitalinos? Su característica principal: ser un salón de baile. Esto es algo representativo, en tanto que actualmente los salones de baile han retomado auge y presencia dentro de la escena lúdica, artística y social costarricense. A diferencia de otros lugares de esparcimiento nocturno como bares y discotecas, éstos han sido creados para responder a la

\footnotetext{
* Claudia Lucía López Oviedo. Colombiana. Antropóloga. Programa de Investigación en Desarrollo Urbano Sostenible (ProDUS), Universidad de Costa Rica, claudialucialopez@ gmail.com

** Paola Salazar Arce. Costarricense. Antropóloga. Programa de Investigación en Desarrollo Urbano Sostenible (ProDUS), Universidad de Costa Rica, psalazararce@gmail.com
} 
necesidad que tienen las personas de expresarse, socializar y entretenerse en torno a la práctica de ritmos populares.

Ahora bien, ¿dónde se encuentra este salón de baile que de repente surge en las propuestas de unos y otros sujetos?, ¿cómo se llama? Estas son algunas preguntas que surgen al momento de desplazarse a cualquier antro o lugar de entretenimiento social. El salón de baile lleva por nombre "Karymar" y se encuentra ubicado sobre la Avenida Central de Guadalupe, frente al edificio Municipal, diagonal al Supermercado Más por Menos, en el cantón de Goicoechea, San José, Costa Rica. El lugar tiene un tamaño aproximado de $120 \mathrm{~m}^{2}$, se abre al público los días miércoles, viernes y sábados; y es visitado por una diversidad de personas que incluye no sólo a los bailarines del swing costarricense, sino también a observadores curiosos, aficionados, profesores y estudiantes del Taller Nacional de Danza y academias de baile, entre otros personajes de la vida urbana josefina.

Desde la entrada, el sonido de la música comienza a mezclarse con los aromas a tabaco y alcohol, y se confunde con los ligeros cuchicheos de la gente que se encuentra al interior. Al ingresar se puede abarcar con una sola mirada la generalidad del salón: unas mesas aquí, otras un poco más allá, miradas que se entrecruzan, algunas muy conocidas, mientras que otras se examinan por primera vez. Ya la música se percibe con toda intensidad, el ritmo del swing retumba en los oídos mientras se hace un esfuerzo por captar el sentido de las letras interpretadas en las canciones.

Entretanto, se contempla una mixtura de luces y sombras a lo largo y ancho del lugar. La pista completamente iluminada con grandes focos de luz amarilla en cada una de las esquinas del techo que la cubre, sobresale imponente y pomposa como el corazón de "Karymar". A su alrededor, la coloración del espacio se distingue por una luz morada de neón y otras en amarillo tenue, fucsia, azul, naranja y rojo. Éstas últimas otorgan un aire de intimidad y calidez a este entorno en el que apenas se insinúan las siluetas.

Cuando se es novato en el ingreso a "Karymar", el ambiente interior se percibe intimidante, oscuro y confuso. Esto responde a una mezcla de sensaciones desencadenadas por las miradas que recaen en la persona que ingresa y es ajena a este ambiente; así como también a la música fuerte y penetrante que le envuelve y a la disposición de un espacio carente de ventanas y otros accesos, provocando que la dinámica del salón se concentre en su interior y no permita un diálogo con aquello que se encuentra por fuera del mismo.

Por el contrario, quienes frecuentan el lugar ingresan con ese aire de natural seguridad que sólo se adquiere cuando más allá de la rutina y la fuerza de la costumbre, se tiene un sentido de pertenencia orgánico con "Karymar", así como una experiencia de vida arraigada a la pasión, el goce y el disfrute de ser bailarín, y de encontrar allí un espacio idóneo para expresarlo y sentirlo.

Así, para entender las dinámicas que suceden en el interior de este célebre salón de baile, hay que pasar más allá de la puerta, retener esas primeras impresiones para los apuntes de recuerdos $\mathrm{y}$, finalmente, atreverse a tomar lugar en una mesa y empezar a observar detenidamente cómo cada detalle y cada parte de "Karymar" lo constituyen como una totalidad espacial donde se hace 
posible el despliegue de una danza que ha trascendido épocas y sectores sociales en la vida de San José.

\section{“Karymar": un amalgama de enseres, música, bailarines y movimientos}

Este salón se compone de un mobiliario modesto y ecléctico. Sus paredes -además de cumplir con su función estructural- se levantan como secciones que concentran la mayor parte de la utilería que da personalidad al lugar y que captan la atención de quien encuentra en su interior.

Aquí se rompen los esquemas masificados de lo que puede o no ser el "buen gusto", pues tanto el espacio como la música y la gente que noche a noche se apropian de éste, han conformado su propio sentido de lo que es atractivo ver, escuchar, tomar, bailar, compartir e incluso usar.

Mesas y sillas de baja altura (aproximadamente 20 en total), cubiertas con telas de color rojo y verde, predominan alrededor de la pista de baile, lo que las convierte en puntos estratégicos de observación y en espacios para la socialización al interior del salón. Para algunos, sin embargo, son tan solo lugares de paso pues el deseo de bailar emerge con toda su fuerza y, entonces, la pista es el lugar que realmente adquiere trascendencia.

La dinámica que se despliega en las mesas permite visualizar mujeres y hombres conversando acompañados de cigarros, buenos tragos de guaro con hielo y limón y unas cervezas Pilsen. Mientras tanto, sus miradas se dejan contagiar por la tentadora pista y sus diestros bailarines. Puede afirmarse que la pista de baile se encuentra ubicada de tal manera que toda la vida interna del salón gira a su alrededor, transmitiendo, que el baile es determinante y trascendental en este lugar y que, en consecuencia, su práctica debe llevarse a cabo en un espacio que sea accesible para todos los que llegan y observable para quienes prefieren quedarse en sus mesas.

De este modo, el escenario o pista de "Karymar" responde a las distintas dinámicas sociales que se pueden desarrollar al interior de un salón como éste. Bailar, hacerse observable a los ojos de otros, al mismo tiempo que la pista se convierte en una totalidad en sí misma, cuya vivencia se hace perceptible y aprehensible sólo para quienes están dentro de ella sintiendo la experiencia del movimiento a través de su cuerpo y del contacto con los otros.

Así, el que está por fuera de ella se deja llevar por la persuasión que envuelve a todos los bailarines que danzan en su interior, pues desde este ángulo, la pista se convierte un espacio necesariamente observable y que puede ser calificado, incluso estando vacía. De este modo, todo lo que ocurre allí dentro se elogia o se descalifica, porque la observación de cualquier baile conlleva siempre a emitir valoraciones y apreciaciones que caen en el bailarín que lo ejecuta.

Por su parte, la música se presenta como un componente que permea cada uno de los rincones del lugar. Dentro o fuera de la pista se siente su presencia, no sólo por el sonido de las melodías o el compás de los bailarines que la hacen tangible con sus movimientos, sino porque genera una serie de sensaciones e impresiones que cada persona vive en su interior.

Cada noche de miércoles, viernes o sábado, sobresalen las melodías de swing criollo, reemplazadas un par de veces por bolero son y una corta mezcla de melodías de salsa, cuya 
presencia no llega a opacar esa distinción y orgullo con la cual "Karymar" se autodefine como La cuna del Swing.

De esta manera, la música que ameniza la mayor parte de una noche en "Karymar" es la cumbia ${ }^{1}$, así como sus derivados al estilo mexicano tex-mex, adaptaciones del ritmo básico de la cumbia para melodías de géneros musicales como el rock, el ska o el pop y que en algunos casos hace referencia a diversos estilos y épocas. Se puede escuchar desde una cumbia colombiana de hace 30 años hasta una canción del momento modificada a ritmo de cumbia ("guacharacha").

$\mathrm{El}$ ambiente se hace y crece a ritmo de las variadas mezclas musicales y se termina de conformar con los cuchicheos de la gente en las mesas, los silbidos, las risas al son de las ocurrencias en la pista de baile, las palmas en conjunto con las canciones que así lo piden y las continuas charlas que se establecen entre quienes comparten la mesa y otros que arriban al lugar. Estos elementos se terminan de amalgamar entre la decoración, el olor de diversos perfumes y el humo de los cigarrillos que consumen quienes se encuentran sentados y observan con detenimiento.

Una noche en "Karymar" representa ese amasijo de elementos que, a su manera, se encargan de darle vida y personalidad al salón. Enseres modestos reciben semana a semana personajes selectos de la trayectoria histórica del swing criollo, así como un insondable grupo de observadores y aprendices curiosos, que es tan diverso como inconstante.

Es por ello que quienes conocen "Karymar" saben que sus bailarines de swing criollo son determinantes en la identidad y dinámicas de interacción que ocurren al interior de este salón. Éstos representan esa población que recurrentemente se puede encontrar en el lugar, lo que les ha permitido ganarse un reconocimiento y un espacio reservado para esta exclusividad. Por tanto no es extraño hablar de la mesa de Elías o la de Ligia, bailarines célebres del swing criollo, cuya presencia es infaltable en las noches de miércoles y sábados y a quienes todos conocen $\mathrm{y}$ respetan.

"Karymar" es, pues, sus bailarines. Éstos le han permitido consolidarse como un espacio para el disfrute del swing criollo, un baile tan atractivo y a la vez tan intimidante para aprender y estudiar. La fuerza y rapidez de sus movimientos, la agilidad de aquellos y aquellas que llevan tiempo practicándolo, la posibilidad abierta de disfrutarlo en colectivo y una música que ha

\footnotetext{
${ }^{1}$ Es importante aclarar que la palabra cumbia hace referencia al género musical folclórico, originario de la costa caribe colombiana; sin embargo, hay bailarines que la utilizan para representar el fenómeno dancístico popular desarrollado en Costa Rica, conocido por otros como swing criollo. Para efectos del presente ensayo se entiende que el swing criollo no es un ritmo musical sino una forma de bailar que fue creada y desarrollada en la segunda mitad del siglo XX; y, aunque muchas veces se le denomina como cumbia, este baile no corresponde a la cumbia característica de los bailes tradicionales colombianos, en la medida en que tanto su estructura como sus características básicas fueron creadas por las clases populares del Valle Central costarricense. En relación con esto se dice que los pasos del swing criollo fueron tomados del swing de las grandes bandas estadounidenses, propias de los años cuarentas y cincuentas; de este modo el swing criollo nació como una adaptación realizada por los bailarines populares de la época, quienes ejemplificaron sus capacidades de creación e improvisación de nuevos pasos, al calor de la cumbia colombiana que entonces era interpretada por las orquestas. Lo anterior permite reiterar el sincretismo cultural que siempre ha existido entre la danza y la música popular, así como la codificación y estructura que les caracteriza.
} 
atravesado fronteras y generaciones, hacen que en "Karymar" se consolide una vivencia corporal y emocional en torno a este baile, y que a la gente que llega por primera vez se le erice la piel a causa de la fascinación por introducirse en un universo social que se alimenta del pasado y se sustenta del presente para sobrevivir.

El grupo de bailarines de swing que se reúne con frecuencia en "Karymar" lo conforman cerca de 20 personas, incluyendo hombres y mujeres; quienes han encontrado en esta práctica en común una manera para identificarse entre sí y distinguirse de otros bailarines populares que se congregan en otros salones. Por eso la gente que baila en "Karymar" son bailarines de "Karymar" y aunque vayan al "Tania" o de vez en cuando se peguen una bailadita en el "Tobogán", "Karymar" siempre será su entorno, ése que les permite vivir la experiencia del swing de manera individual y colectiva, así como ser reconocidos por los otros y ser capaces de reconocer a esos otros que comparten lo mismo.

Es una cuestión que va más allá del espacio, pero que requiere del espacio mismo para que el desarrollo de las experiencias y las relaciones que dan sentido de pertenencia e identidad a esos grupos, sean hechos sociales posibles y legítimos dentro de cada individuo y de la colectividad.

Así, en la variedad de bailarines de "Karymar" se encuentra la vieja guardia conformada por personas que tienen entre 30 y 60 años de edad; la cual es, quizá, la más constante en frecuencia de asistencia al lugar. Esto se relaciona con el hecho de ser una generación en donde se congrega gente que fue gestora de la práctica de este baile, que además tenía una tradición consolidada en torno a la asistencia a salones de baile en San José y que tiene consigo una forma de pensar sobre el mismo y sobre la estética que lo identifica.

El vestuario constituye una parte importante en el acto de bailar. Las mujeres, con sus cabellos desatados, sobresalen en la pista de baile por sus acuciosos movimientos y cadencias, cuya atención se estimula gracias a las minifaldas y jeans ajustados al cuerpo así como por las blusas sin mangas y con escotes, y una variedad de zapatillas de tacón que se encargan de darle un aire de sensualidad a cada paso ejecutado. Los hombres por su parte se engalanan con una camisa, pantalones y zapatos de vestir, sin olvidar el detalle de las cadenas gruesas de oro y anillos que exhiben con orgullo sobre su cuerpo.

De esta manera, parte de esa vivencia interna que experimentan los bailarines de la vieja guardia con el swing criollo se encuentra influenciada por el hecho de que salir a bailar semana a semana es una tradición cuya emoción se alimenta desde el momento mismo en que todo el cuerpo se dispone para dejarse llevar, entre el calor y el sudor que acompañan cada baile en la pista. Todo esto es parte de una actitud y de una disposición previa a la práctica misma del baile e, incluso, a estar en "Karymar". Hasta cierto punto hay una preparación que supone significados sobre lo que se desea enseñar, sobre cómo se quieren ver, cómo quieren que otros los vean y sobre la ropa y accesorios necesarios para esto.

\footnotetext{
${ }^{2}$ El "Tania" y el "Tobogán" son dos salones de baile popular, muy conocidos por quienes practican el swing criollo $\mathrm{y}$, en general por aquellas personas que gustan de la práctica de ritmos populares como salsa, merengue, bolero, cha cha chá, tango, entre otros. El salón "Tania" se ubica en el barrio Plaza Víquez y el "Tobogán", diagonal al periódico La República, en barrio Tournón. Ambos pertenecen al cantón de San José.
} 
En consecuencia, actualmente "Karymar" se ha visto como el lugar en donde aún este grupo puede disfrutar del swing criollo en su esencia. El cierre de muchos salones y el cambio hacia modelos de espacios como los bares, en donde ni la pista ni el baile ni el swing tienen relevancia, hicieron de "Karymar" un nicho idóneo. En su interior el espacio ha abierto la oportunidad para lo observable, es decir, para el baile y con ello, para lo que se ha convertido en algo repertoriable para los mismos bailarines. Allí se hace posible entonces el despliegue de los movimientos corporales a través de los cuales el swing se comparte y se vive como medio de expresión.

La vieja guardia de bailarines reúne entonces a los pioneros, a los maestros, y a los artífices. Ellos han vivido desde adentro la trayectoria del swing criollo y en sus recuerdos están presentes las épocas de gloria, en las cuales al ritmo de las cumbias colombianas y dando paso al arte de improvisar y crear, originaron un baile popular enigmático, cuya interpretación atrapa la atención de las miradas, atrayendo y provocando a todo el que se deja llevar por la agilidad de sus bailarines y el compás de la música.

Por su parte, las generaciones de bailarines más jóvenes de swing que asisten al salón, cuyas edades oscilan entre 18 y 29 años de edad; a diferencia de la vieja guardia, rotan con más agilidad aunque no dejan de tener el vínculo con el lugar. Su frecuencia con que asisten a este lugar, no está determinada por toda una tradición y arraigo histórico con la práctica del swing. Lo anterior no excluye el hecho de ser personas identificables dentro de "Karymar", es decir que ellos también son reconocidos dentro del lugar por todo ese grupo de actores sociales que en su interior confluyen.

En medio de esta heterogeneidad de gustos la nueva guardia -como también se les llama- reúne a las generaciones de reemplazo del swing criollo. Gracias a esto, el baile adquiere dinamismo y se recrea al compás de las interpretaciones y los significados que éstas configuran como hijas de un contexto social, cultural e histórico que ha permeado sus motivaciones y actitudes en torno a la práctica del swing.

Es así que tanto vieja como nueva guardia se han apropiado física y simbólicamente del lugar, pues la asistencia mayoritaria de cualquiera legitima la posición que tienen en ese día, en ese momento y les da seguridad dentro y fuera de la pista. Por ello, no es de extrañar que durante la noche de un miércoles la mirada se desvíe hacia algunos bailarines de la vieja guardia, mientras éstos observan atentos cómo se mueven y cómo interpretan el swing los más jóvenes, manteniéndose en su mesa con "su gente", sin siquiera salir a bailar en la pista. Pareciera que evaluaran lo que hacen los otros, esos otros que poco a poco les reemplazan y que hacen del swing un baile actual, vivo y en constante renovación.

Lo anterior no excluye el hecho de que cualquier miércoles o sábado, exponentes de una u otra generación se compenetren en el "espacio de los otros", lo que suscita ese proceso de construcción de identidades a partir de la otredad, definiendo papeles, características y, además, valoraciones sobre lo que se es frente a ese otro y sobre lo que ese otro representa para sí mismo. Gracias a ello se hace posible hablar de grupos de bailarines de swing criollo que se reúnen periódicamente en "Karymar" en torno a una práctica que ha determinado sus escogencias y 
preferencias en el entramado cultural de los bailes populares, y que les ha permitido reconocer un aspecto más que les define como individuos, que los diferencia de otros. Como resultado se generan dinámicas de interacción e intercambio de la experiencia compartida al calor de las cumbias y las luces multicolor.

La vivencia del swing en "Karymar", además de congregar grupos, supone considerar las valoraciones y significados que se comparten. Gracias a éstos se hace posible la integración, la frecuencia de asistencia al lugar y el distanciamiento de quienes al encontrarse por fuera de este entramado de movimientos y sonidos, no pueden compartirlos.

De lo anterior se desprende el hecho de que el salón "Karymar" pueda constituirse como un lugar idóneo para la confluencia social en torno a la práctica de este ritmo. A la par de su disposición física y esa estética particular que combina en un espacio relativamente pequeño una gran diversidad de elementos decorativos, el salón "Karymar" se comienza a entender como el contexto en donde tienen cabida las relaciones entre los bailarines de swing criollo, atravesadas por la experiencia de sentir juntos el baile, de darle una continuidad histórica, de compartir la pista, el gusto por ciertas melodías y todo ese intangible cultural que noche tras noche se recrea entre el cuchicheo, las risas, el humo y, por supuesto, el calor de unos buenos brincos.

Por ende, se puede afirmar además que la experiencia del swing criollo en "Karymar" también es consecuencia de una forma de posicionarse frente al mundo globalizado, desde una perspectiva local de todo lo relacionado con lo lúdico y las formas de entretenimiento que cotidianamente se legitiman en y a través de los medios masivos de comunicación. Así, el baile se convierte en hecho social que responde a las necesidades expresivas de una población que semana a semana se reúne en el salón de baile a experimentar junto a los otros la disposición del cuerpo en la pista para la ejecución de saltos y movimientos que les harán recordar quiénes son al interior de ese lugar y lo que saben sobre ese fenómeno.

El baile se convierte además en acción que a través de gestos corporales intencionales manifiesta un modo de vida y un lenguaje social particular que gira en torno al cuerpo sensible, a la valoración de un ritmo particular sobre otros y a la organización de la vida cotidiana tomando como referencia esas pasiones y deseos que desatan en el bailarín la búsqueda de un entorno en donde desplegarlos.

Se podría decir que bailar swing en "Karymar" vuelca el entretenimiento hacia la exaltación del cuerpo mismo y de una serie de emociones y sensaciones que esto provoca, las cuales se vinculan con el sentir de cada sujeto y con el contacto que se adquiere con la pareja o compañeros de baile. De esta manera, toda la experiencia confluye en estructuras dancísticas llevadas a cabo siguiendo cierto orden, de modo que lo que se ve en la pista y lo que se siente dentro de ella sea algo armónico y a la vez fuerte y determinante en ese entramado de momentos y circunstancias que rodean la vida de cada persona que asiste a este lugar.

Retomando lo anterior, se debe recordar que los bailes han estado presentes en nuestra historia como especie humana y por ende se han constituido como medios de expresión de creencias y valores transmitidos al interior de cada grupo cultural; además han servido como elementos de 
cohesión, intercambio y esparcimiento, al interior de los distintos espacios en los que se han efectuado. Es decir que en sí mismos guardan representaciones e imaginarios de lo que han sido las distintas sociedades, como también, ellos mismos han sido representados e imaginados por quienes los han practicado y también por quienes no lo han hecho, sea por prejuicio, desinterés o falta de motivación.

De esta forma se ha encontrado que entre bailarines y baile se construye un diálogo, en el que van impresos significados sociales e individuales que han facilitado el desenvolvimiento de hombres y mujeres en este universo de música, ritmos y movimientos; así como las relaciones entre ellos mismos establecidas. Igualmente, es importante tomar en cuenta cómo bailarines hallan en el baile una identidad y un sentimiento de pertenencia a un grupo; esto a través de los procesos de aprendizaje y los espacios de baile en los cuales se ven involucrados, a través de la transmisión y la reinvención.

Por consiguiente, desde la antropología costarricense es importante abordar la temática del baile ya que, hasta el momento no se ha realizado investigación alguna, sobre baile popular y en sí sobre el swing criollo y su importancia dentro de la cultura popular. En consecuencia, es evidente el vacío conceptual, contextual y teórico sobre el baile del swing criollo, y sobre cualquier baile popular inmerso en la vida urbana y en ese mundo social que subyace a los salones de baile y a las representaciones que en su interior se configuran. En cuanto a la realidad que se halla en el salón Karymar, se ha observado la importancia que tiene la práctica de este ritmo entre los bailarines; no sólo como la experiencia recreativa y de esparcimiento que representa la preferencia por el lugar y la actividad dancística que allí se genera, sino también, por el hecho de encontrarse y compartir en colectivo conocimientos y vivencias alrededor del swing.

Así, un abordaje antropológico del baile del swing criollo contribuye con la visibilización de una parte en constante revitalización de la cultura popular y urbana de la Gran Área Metropolitana, así como de todo el territorio nacional. En este sentido, permite visualizar y redescubrir esos imaginarios sociales que han fundamentado el hecho de que el swing criollo pueda pensarse como un referente cultural dancístico que ha identificado y cohesionado a distintas generaciones de bailarines dentro de la historia misma de los salones de baile.

Por ende, todo fenómeno dancístico merece una especial atención dentro de la antropología, en tanto que implica un universo de imaginarios únicos que ilustran las realidades sociales en las que se desenvuelven aquellos sujetos que son precursores y artífices de toda una forma de expresión y reconocimiento en el entramado cultural urbano. 